\title{
DEVELOPMENT OF REFLECTIVE COMPETENCE IN STUDENTS IN TECHNICAL UNIVERSITIES OF RUSSIA
}

\author{
Lyudmila Panova*, Natalya Plugina, Alexander Kaminsky, Elena Kondrashova, Inna \\ Guryanova, Natalya Martynova \\ Nosov Magnitogorsk State Technical University, Magnitogorsk, Russian Federation
}

\begin{abstract}
One of the main problems of the modern higher education system in the Russian Federation (RF) is underrepresentation of knowledge in the educational process as a factor that determines not only the content of thinking but also the personality content. Hence, it updates the issue of providing pedagogical conditions for the development of students' ability to reflect, which causes quality changes in the self-awareness structure. Through expansion, its cognitive components ensure positive developments in self-formation of future specialists and their self-adjustment. Based on a literary review, the article analyzes and substantiates the reflection concept content. By means of interviewing, the level of the reflective competence in students in the process of solving problems was analyzed through the example of mechanic engineering students of Russian universities. Based on multidimensional factor analysis, structural (constructive and situational-destructive) factors of students' reflection in the educational process were identified. Student clusters were formed and substantiated by the growth rates of reflective competence factors. The optimal development level of the situational-destructive factor in student reflection in the process of solving problems was determined. Education technologies for developing reflective competence in students were elaborated. Parameters of pedagogical reflection development in the educational process were substantiated. A pedagogical experiment was conducted to assess the effectiveness of the proposed pedagogical conditions for the formation and development of reflective competence in students in the Russian universities under study. The research of the problem of reflection development in students in the higher education system of the Russian Federation makes a certain contribution to pedagogical science and teaching practice and opens up new opportunities for the student educational process.
\end{abstract}

Key words: Reflection; Reflective competence; Higher education system; Pedagogical conditions; Reflective educational technologies; Educational process; Processing; Reflectivity

\section{INTRODUCTION}

The strategic goal of the modern higher education system in Russia is the formation of a personality capable of creative thinking and independent action [1]. Consequently, it requires a focused effort of a teacher on the development of reflection in students as a necessary element of active educational and cognitive work. The development of reflective skills helps to match the actual knowledge acquired in the higher education system with practical implementation [2]. The importance of interdisciplinary research and interdisciplinary education has increased being focused not so much on formal qualifications as on obtaining modern key competences as the ability to make decisions in a dynamic environment, the ability not so much to reproduce academic knowledge as to create new knowledge through thinking and communication and to act in accordance therewith. Obviously, the development of reflective thinking in students as the intellectual potential of any country is a priority of the higher education system of the Russian Federation in the modern context [3]. The federal state higher education standards, bachelor, specialist, and master degree programs as well as preparation of highly trained personnel provide for the application of innovative training session forms to ensure the implementation of educational activity in universities [4]. Meanwhile, the practical development and introduction of professional educational technologies that determine the development of reflective skills in students in the educational environment of Russian universities have not been sufficient [3]. The result of the ongoing reforms aimed at the higher education modernization has been insignificant because of incompleteness of the changes made [5]. The current situation is contingent on a number of factors. First, reflective activity pedagogy seems to be a relatively new and insufficiently developed academic discipline [3]. Second, the majority of teaching staff in Russian universities do not possess reflective activity technologies for working with students $[6,7]$. Third, the influence of a destructive psychological factor associated with teachers' opinion of on no need to intentionally develop reflective abilities, competencies, and culture in broader terms in future professionals [7]. They attribute it by these skills manifesting directly in the graduation process or as a secondary educational effect or as a result of professional (quasi-professional) experience accumulation. Such an approach poses professional training risks in the educational system resulting in graduates not meeting the needs of the current volatile market conditions. In this regard, the purpose of the research was to elaborate conceptual recommendations on a pedagogical groundwork for the development of reflective competence in students in the process of solving problems through the example of en- 
The boundaries of students' reflection levels are defined by Fibonacci scale [10]:

$$
\left\{\begin{array}{l}
s_{1}=s_{\min }+0.38 *\left(s_{\max }-\right. \\
s_{2}=s_{\text {min }}+0.62 *\left(s_{\max }-\right.
\end{array}\right.
$$

where $\mathrm{s}_{\min }$ is the minimum possible score;

$\mathrm{S}_{\max }$ is the maximum possible score.

A low level of reflection corresponds to a range of scores [ $\mathrm{s}_{\min } ; \mathrm{s}_{1}$ ], the medium one is $\left(\mathrm{s}_{1} ; \mathrm{s}_{2}\right]$, the high one is $\left(\mathrm{s}_{2}\right.$; $\left.s_{\text {max }}\right]$.

To analyze the structure of student reflectivity, the method of multidimensional factor analysis was used. The composition of factors is determined based on factor loadings. The factor loadings $>|0.7|$ are statistically significant for assigning a variable to the factor composition [11].

The values of factor loadings are calculated by equation (4) based on the principle of minimizing deviations of the covariance matrix obtained after estimating factor loadings of the covariance matrix of initial indications [11].

$$
Z_{i}=a_{1}{ }^{*} F_{1}+a_{2}{ }^{*} F_{2}+\ldots+a_{i}{ }^{*} F_{i}+\varepsilon
$$

where $Z_{i}$ is the standardized value of an indicator;

$a_{i}$ is factor loadings;

$F_{i}$ is factor values;

$\varepsilon$ is model residuals.

The clustering method is used to group students by the growth rate of the development of reflective competence in solving problems. Out of the cluster analysis varieties, Kohonen neural networks were used to make to improve the clustering accuracy based on a combination of linear and nonlinear relationships. Clustering is based on a minimization criterion of Euclidean distances between the objects of one cluster [12]:

where $d_{i j}$ is the distance between the $\mathrm{i}$-th and $\mathrm{j}$-th objects

$$
d_{i j}=\sqrt{\sum_{k}^{n}\left(x_{i k}-x_{j k}\right)^{2}} \rightarrow \min
$$

of the cluster;

$x_{i k}$ is the value of the k-th index of the i-th object;

$x_{j k}$ is the value of the k-th index of the j-th object.

To assess the constraint force between the students' reflection index movement and their academic performance, a pair correlation coefficient (Equation 6) was used [13]:

where $r_{x y}$ is the correlation coefficient between the

$$
r_{x y}=\frac{\sum_{i=1}^{m}\left(x_{i}-\tilde{x}\right)\left(y_{i}-\bar{y}\right)}{\sqrt{\sum_{i=1}^{m}\left(x_{i}-\bar{x}\right)^{2} \cdot \sum_{i=1}^{m}\left(y_{i}-\bar{y}\right)^{2}}}
$$

growth rates of students' reflectivity index and their academic performance;

$x_{i}$ is the value of growth rates of students' reflectivity index; $y_{i}$ is the value of students' academic performance indicator expressed on a scale from 1 to 100 ; 
$\bar{x}, \bar{y}$ are the average values for the survey period of the growth rates of students' reflectivity index and academic performance, respectively;

$m$ is the number of periods.

The value of the correlation coefficient $|0.1|-|0.3|$ stands for a weak constraint force; $|0.3|-|0.5|$ moderate; $|0.5|$ - |0.7| - noticeable; $|0.7|-|0.9|$ - high; $|0.9|-|1|$ - very high.

A further stage of the study was to establish the character of the dependence of students' academic performance on the development level of the situational-destructive reflection factor that can have a positive and negative impact on academic performance. For this purpose, correlation regression analysis was used, its model having the following form [14]:

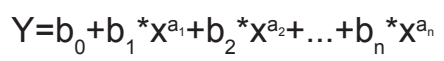

where $Y$ is the academic performance level of students, expressed on a scale from 1 to 100 ;

$\mathrm{x}$ is the development level of the situational-destructive factor in terms of scores;

$b_{0}$ is an intercept term;

$b_{1, \ldots, n}$ are the independent variable coefficients;

$a_{1, \ldots, n}$ are polynomial degrees.

The regression model parameters $\left(b_{0}, b_{1, \ldots,}, a_{1, \ldots, n}\right)$ are estimated by the least square method. Its summary is a selection of model parameters whereby the sum of squares of deviations of the actual values of a dependent variable from the predicted ones is minimized [14]:

$$
\sum_{i}^{N}\left(Y_{i}-\overline{Y_{i}}\right)^{2} \rightarrow \min
$$

where $Y_{i}$ is the actual value of the dependent variable in the $i$-th period;

$\bar{Y}_{i}$ is the predicted value of the dependent variable in the i-th period;

To assess the effectiveness of assignments proposed in the work to improve the level of students' reflection, a pedagogical experiment was used. The experiment involved formation of a control and experimental group of students. The effectiveness is assessed through a comparison of the level of reflection in the experimental group students trained according to the proposed method of reflection development and the control group where assignments and trainings to improve the reflection level were not used.

The statistical significance of a pedagogical experiment, that is, the significance of differences in the level of reflection development in the control and experimental group students is estimated by Student's t-test calculated according to the following formula [9]:

$$
t=\frac{M_{1}-M_{2}}{\sqrt{m_{1}^{2}+m_{2}^{2}}}
$$

where $M_{1}$ is the average score that describes the reflection level in the experimental group students;
$M_{2}$ is the average score that describes the reflection level in the control group students;

$m_{1}$ is the mean experimental group error; $m_{2}$ is the mean control group error.

A hypothesis of statistical significance of the pedagogical experiment results is validated if the calculated value of the Student's t-test (Equation 9) exceeds the tabulated value [9].

\section{LITERATURE REVIEW}

The definition of reflection has become quite widespread in the pedagogical discourse. In addition, modern psychological, philosophical, and sociological theories, as well as theories of social communication, public administration, management, etc., whereby the reflection concept is also widely used, influence pedagogical conceptualization of reflection to a significant extent $[2,15,16]$. In 1999 R. Holland made an attempt to unite approaches to the essence of reflection as one type of personal reflection in various concepts of the humanities [3]. Based on integrated approach, the scientist distinguished four reflection types. What he refers to as the first type is reflection as a phenomenon limited to only one area of scholarly knowledge studied within the following concepts: reflective sociology and reflective prediction, the theory of personality constructs, and Mead's concept [17]. The second approach considers reflection as being integrated with other concepts from the standpoint of comparing approaches or as an eclectic integration without an in-depth analysis of the theoretical approaches: a descriptive theory and Morgan's concept [18]. The understanding of reflection considered in psychoanalytic concepts and social psychotherapy approaches as a process of self-cognition that allows an individual to develop understanding of their own actions is referred by R. Holland to the third type of reflection [3]. The last, fourth type of reflection was formulated by R. Holland as a human ability allowing an individual to understand and foresee the boundaries of their existence, whereby social units are formed [3].

A significant contribution to the study of reflection as a feature of an individual psychological reality has been made by G.P. Shchedrovitsky who views reflection as a process of forming relations and interpersonal communications between individuals by means of a reflective transcendence based on five stages: stopping, fixing, objectifying, discussing, and symbolizing [19]. Reflective activity of a person occurs when they regard their activities as wrong. At the same time, while being motivated to obtain a desired result in the future, the individual begins to analyze meaningfully how to act differently to achieve the goal [2]. As a thinking process, reflection has also been considered by such scientists as $\mathrm{S}$. Atkins and $\mathrm{K}$. Murphy. The scientists identified three reflective process components: awareness, critical analysis, and a new perspective of a situation [20].

One of the most famous modern reflection concepts is 
the concept of a reflective practitioner, American philosopher and teacher Donald Sean, that is extensively used by the world educational community [21], especially in the field of professional training for such specialists as teachers, physicians, community development workers, etc. [16, 20]. The concept results provided an understanding of the problem of nature of reflection and the educational process organization, since the scholar substantiated differences between reflection in action and reflection on an action. Thus, reflection on an action arises in a person after a certain outcome of events with the aim to form new hypotheses for the problem solution. Yet, reflection can also arise in the process of a person thinking and understanding what they are doing at the time when they are doing it [22].

The scientific results of D. Sean laid the groundwork for the studies of J. Scanlan and W. Chernomas describing several stages of the reflection development in the process of training nurses: self-awareness, description, critical analysis, synthesis, evaluation, and perspective [23]. It is the final stage of reflection that testifies to its interpretation as individual aptitude of a person to realize a situation, which causes future effective, cognitive, and behavioral changes. This theory also reflected in the works of Yu. N. Kulyutkin, who has studied reflection in the personality self-regulation structure [23].

Later concepts considered reflection in the structure of general human abilities as a fluid and adaptive process of the psychic system self-transcendence arising at the recursive consciousness level (R. Zelazo [24], A.V. Karpov [25] and I. M. Skityaeva [26]).

These concepts represent a certain aspect of reflection or its manifestation patterns, considering it as part of the cogitativity process or as thinking. Meanwhile, however, it should be noted that in the case of attributing reflection to the process of thinking and cogitativity, it can be stated that reflection is aware of the mental content and reflects the entire thought content. This means that reflection is placed on the supersystem level in relation to the human consciousness and thinking. Only by understanding reflection as a person's ability to consciousness and thinking can one assert that there is a certain component within the psychological system of an individual that contributes to a peculiar system operation. The form of self-awareness and thinking depends on the features of reflection, that is, on an individual's practical attitude to themselves and to their living environment. In other words, the form of reasoning and cognition is the result of the functioning or development of a certain reflection type (comparing, considering, transcending or defining). This approach to understanding the reflection essence is supported by the research of I.Ya. Berland, who argues that reflection is not absorbed from culture, whereas ways of human actions transmit through communication with other people [27]. Also, I.S. Kon in his works elaborated on the social nature of reflectivity in relation to individual self-knowledge in concrete terms [28]. It is functional and reflective components of self-awareness that contribute to a change in self-knowledge (J. Schneider) [29].

Thus, within the framework of this research, reflection is understood to mean an individual's ability to rethink the content of personal self-awareness in a problem-conflict situation in order to ensure a comprehensive identity.

The importance of personal reflection in students in the higher education system should be noted, contributing not only to comprehending the integrity of a situation and all the implementation conditions, but also to comparing their own capabilities by irradiating knowledge about themselves without resorting to the trial and error method. However, the authors emphasize the insufficient degree of conceptual development of this phenomenon from the perspective of providing pedagogical conditions for the reflection development in the educational process.

\section{RESULTS}

Reflection as a component of an active semantic center of a personality helps to establish a link between the cognitive and emotional spheres in a personality, to unite the object-transforming activity with its universal target criteria (values-based attitude). Formed by the time of admission to university, students' reflective abilities are underdeveloped, and special knowledge acquired by students does not serve as a way to update the activity-based attitude to the world, to people, and to themselves as a whole.

Formation and development of the reflective competence in students suggests that the knowledge acquired by students in the process of university studies constitutes the basis for explaining and understanding its meaning as an event in the activity experience continuum [6]. This becomes a reality if the development of reflection in students does not only contribute to their self-conception in conjunction with the outside world and other people, but also provides a link between understanding the meaning of a text (a sign) and self-conception.

The current educational process in the system of higher education in Russia is not focused on the reflection development, since there is a significant separation of theoretical instruction from practical training with no connection between the intellectual and emotional spheres. The educational process neutralizes the approach of multivariate, dialectical logic and divergent thinking and is primarily based on the principles of formal logic and the development of convergent thinking in students. To confirm the research findings through interviewing of engineering students, the level of reflective competence formedness in students in terms of solving problems in Russian universities was determined.

The list of interviewing questions for assessing the level of students' reflection in solving problems was formed according to O.S. Anisimov's methodology for determin 
ing the reflection thinking [30] and A.V. Karpov's methodology for determining the level of personality reflection development [25].

It was suggested that the level of student reflection in solving problems should be assessed according to the following statements (interviewing questions), whereby the students were asked to give their estimates in the range from 0 to 5 , where 0 stands for a complete negation of a statement, and 5 means an unconditional consent:

1. Performing any work requires mental planning (No. 1).

2. In the process of solving a problem, I weigh all the pros and cons (No. 2).

3. Before starting work, I think about its ramifications (No. 3).

4. I model the process of accomplishing a task in detail, considering alternate solutions (No. 4).

5. Having solved a problem, I need to discuss it (No. 5).

6. I often regret the results obtained when performing a task (No. 6).

7. I always have clear guidelines that allow me to control the process of accomplishing a task (No. 7).

8. I need a lot of time and energy to understand what I want (No. 8).

9. After solving a problem, it takes me a long time to question the decision (No. 9).

10. Having made a mistake, I find it hard to switch to another task (No. 10).

11. Preparing to solve a difficult problem, I think about its solution even when I am engaged in other activities (No. 11).

12. While doing any work, I clearly see the tasks set for myself (No. 12).

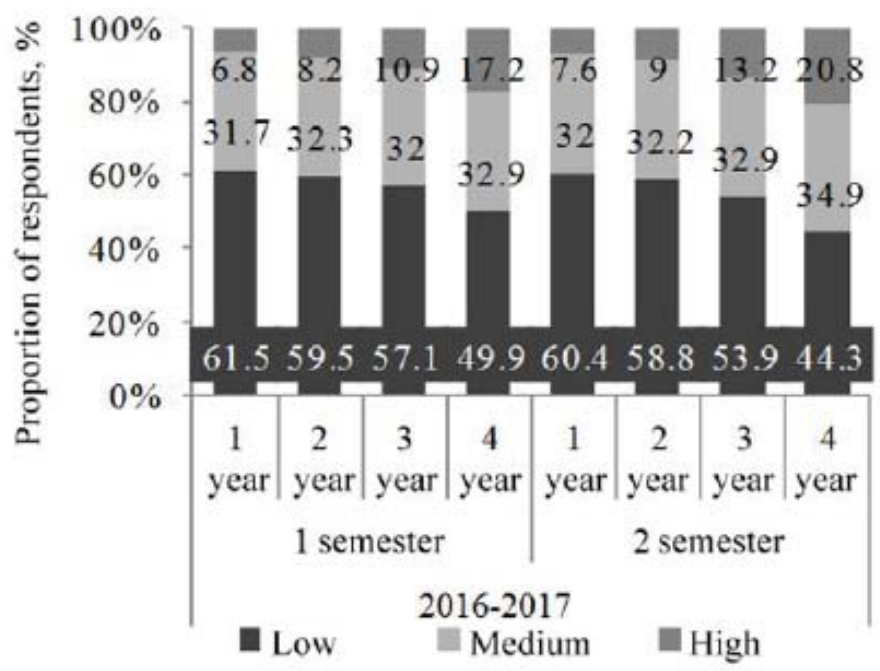

13. It is hard for me to make an important decision (No. 13).

14. I always deliberate and analyze the reasons for my failures (No.14).

15. I always find the reasons for my failures (No. 15).

16. I always blame myself for failures in solving group problems (No.16).

17. All my decisions are calculated and carefully weighed (No.17).

A research to measure the level of reflection in students was conducted in groups of the first to fourth year mechanic engineering students majoring in "Machine-Building Technologies" at the Bauman Moscow State Technical University (Bauman MSTU), in "Mechanical Engineering" at the Gubkin Russian State University of Oil and Gas (Gubkin University); in "Handling, Transport, Construction, Road-Building Machinery and Equipment" at the Moscow Automobile and Road Construction State Technical University (MADI) throughout 2016-2017, 20172018 academic years and at the end of each semester.

The real time reflection level studies make it possible to assess its impact on performance in terms of students' academic performance. In addition, the participation of first to fourth year students as respondents have allowed the researchers to take into account the personality age factor in the process of reflective competence formation, revealed in the studies of I.N. Semyonov and S.Yu. Stepanov. The scholars have demonstrated a direct correlation between personality-reflective manifestations and age rates [31].

The study involved 400 students. Exceeding the minimum number of respondents required by equation 1 as well as coverage of all the instructional years at the undergraduate level (1st-4th years) indicates the respondent sampling representativeness to ensure the validity of interviewing results.

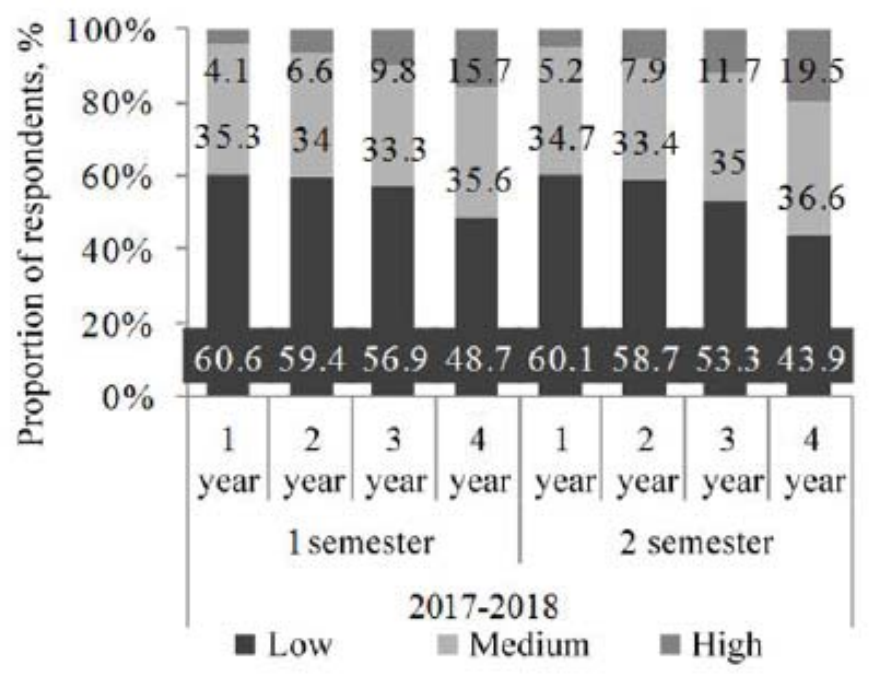

Figure 1: The testing results for students' reflection levels when solving problems (average for the universities included in the sample totality, \%) 
Processing the interviewing results to determine the reflection level in students when solving problems involves a calculation of a final grade (score) according to the students' answers and its grading by levels. Since all the questions were designed as stimulators in determining the level of reflection (the higher the score is, the higher the level of reflection is), the final score was calculated by summing up the scores on all the questions.

To determine the quantitative limits of the reflection levels, the Fibonacci scale was used (Equation 3). The minimum possible score based on the test results was 0 points, while the maximum possible was 85 points. Based on the minimum and maximum scores, the student reflection levels were determined:

low - [0; 32];

average - $(32 ; 53]$;

high - $(53 ; 85]$.

The mechanic engineering student reflection level testing results at the Bauman MSTU, the Gubkin University, and the MADI are shown in Figure 1.

According to the study, the number of students with a low level of reflective competence formedness in solving problems ranged within $44.3 \%$ and $61.5 \%$ in the 2016 2017 academic year. The medium level of reflection was characteristic of $31.7 \%$ to $34.9 \%$ of students, while a high level was characteristic of $6.8 \%$ to $20.8 \%$. In the 2017 2018 academic year, a low level of reflection has been determined in 43.9 to $60.6 \%$ of students. The medium reflective competence level was characteristic of $35.3 \%$ to $36.6 \%$ of students, high - of $4.1 \%$ to $19.5 \%$ of students. The highest index of reflection is observed in the fourth year students in the second semester. The lowest level of reflective competence in solving problems is found in first year students in the first semester. In other words, one can testify based on the interviewing results that a preponderance of mechanic engineering students in Russian universities is characterized by a low level of reflective competence in solving problems regardless of the instructional year. Meanwhile, there is an upward trend in the reflection levels in the first to fourth year students.

The statistical significance of the test results is confirmed by the sample representativeness assessed with Equation (1), and a weak variability of individual test results within each course, assessed with Equation (2). A low level of variation in the test results made it possible to determine the average development level of student reflection in the context of academic curriculum.

To determine the structure of students' reflectivity, factor analysis was carried out based on the interviewing results. The objects (variables) for the factor analysis were scores of the first to fourth year mechanic engineering students of the Bauman MSTU, the Gubkin University, and the MADI when answering the interviewing questions (No.1-17). SAP Statistica 10 was used for the analysis.

The number of factors is determined by Kaiser test, whereby those factors for which the eigenvalues are greater than 1.0 are considered statistically significant (Table 1).

Table 1: The eigenvalues of reflectivity factors in mechanic engineering students in solving problems Bauman MSTU, Gubkin University, and MADI

\begin{tabular}{|l|l|l|l|l|}
\hline Value & $\begin{array}{l}\text { Eigen- } \\
\text { value }\end{array}$ & $\begin{array}{l}\text { \% Total } \\
\text { variance }\end{array}$ & $\begin{array}{l}\text { Cumu- } \\
\text { lative } \\
\text { Eigen- } \\
\text { value }\end{array}$ & $\begin{array}{l}\text { Cumula- } \\
\text { tive \% }\end{array}$ \\
\hline 1 & 3.56 & 54.02 & 3.56 & 54.02 \\
\hline 2 & 2.13 & 32.32 & 5.69 & 86.34 \\
\hline
\end{tabular}

Table 2: Factor loadings of the interviewing indicators to determine the reflection levels in the Bauman MGTU, the Gubkin State University, and the MADI students in solving problems

\begin{tabular}{|c|c|c|c|c|c|}
\hline Factor & $\begin{array}{c}\text { Indicator (interviewing } \\
\text { question) }\end{array}$ & Factor loading & Factor & $\begin{array}{c}\text { Indicator (interviewing } \\
\text { question) }\end{array}$ & Factor loading \\
\hline & No.1 & 0.85 & & No.6 & 0.88 \\
\hline & No.2 & 0.79 & & \multirow{2}{*}{ No.8 } & \multirow{2}{*}{0.79} \\
\hline & No.3 & 0.84 & & & \\
\hline & No.4 & 0.86 & & \multirow{2}{*}{ No.9 } & \multirow{2}{*}{0.71} \\
\hline & No.5 & 0.78 & & & \\
\hline & No.7 & 0.92 & & \multirow{2}{*}{ No.10 } & \multirow{2}{*}{0.81} \\
\hline & No.11 & 0.76 & & & \\
\hline & No.12 & 0.81 & & \multirow{2}{*}{ No.13 } & \multirow{2}{*}{0.76} \\
\hline & No.14 & 0.92 & & & \\
\hline & No.15 & 0.73 & & \multirow{2}{*}{ No.16 } & \multirow{2}{*}{0.83} \\
\hline & No.17 & 0.77 & & & \\
\hline
\end{tabular}



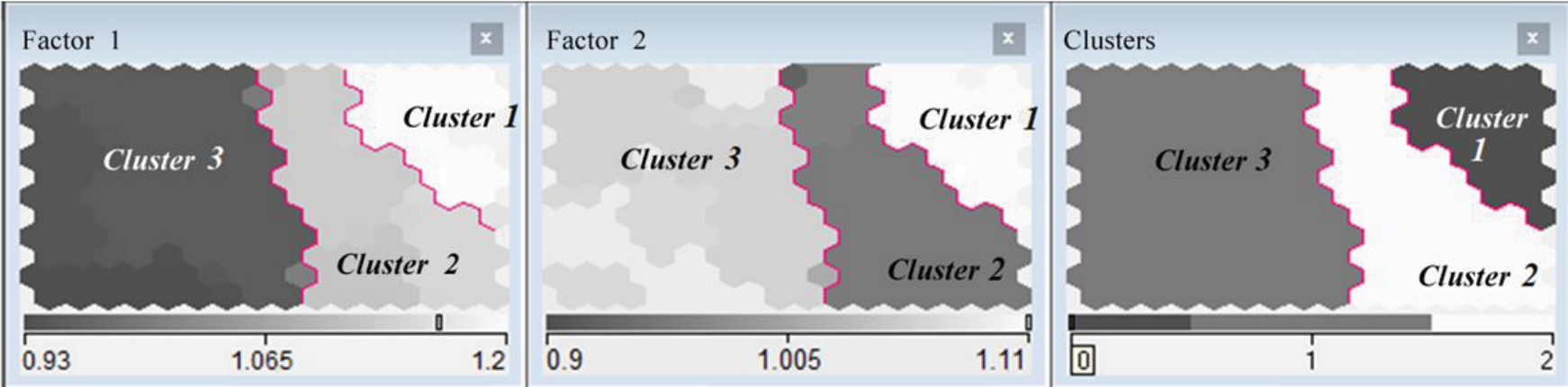

Figure 2: The mechanic engineering student clusters by the development trends in the levels of reflective competence when solving problems

identified according to the development trends in the reflection levels when solving problems (Figure 2).

Three clusters is the optimum number selected. This is due to the fact that for this number of clusters, the percentage of recognized objects is maximized (90.48\%), while the model bug is minimized. The percentage of recognized objects means that for two out of the 21 observation objects, a cluster characterizing the development trends in the reflection levels was not uniquely determined. For the other 19 objects, the results were unambiguously interpreted. The error level for the learning and test sets, determined by the program at the ratio of $90 \times 10 \%$ in a random manner, does not exceed $5 \%$. This indicates the adequacy of student grouping results by the trends in the level of reflective competence in solving problems. The composition of clusters and their statistical characteristics are presented in Table 3.

As the study for the survey period has shown, Cluster 1 has the highest rates of reflection development factors: Factor $1:+16 \%$ and Factor $2:+10 \%$. Cluster 2 is characterized by different trends in the reflection factors development. Thus, Factor 1 is characterized by the growth rate of $+8 \%$, which is two times as low as the growth rate of the constructive factor in the Cluster 1 students. Factor 2 reflects a downward development trend: - 6\%. Cluster 3 students are characterized by the lowest growth rates of reflection factors, while the growth rate of Factor 1 is $4 \%$, and the growth rate of Factor 2 is $+7 \%$.

Based on the findings of trend studies in the reflective competence development level in mechanic engineering students, it can be concluded that the highest rates of growth in the reflection levels are observed in the fourth year students (7th and 8th semesters) and in those years where sociological and psychological subjects are taught: "Sociology" at the Bauman MSTU (2nd semester), "Social Psychology" in the Gubkin University (2nd semester), "Sociology" in the Gubkin University (6th semester). In the MADI where sociological and psychological subjects are not taught the lowest level of reflection and the lowest growth rates were observed.

It should be noted that the constructive factor has no limitations in the development of reflective problem solving skills in students. The higher the level of this factor is, the higher the formedness level of the reflective competence is. Concerning the situational-constructive factor, an increase in the reflection levels due to this factor stimulation will to a certain point help to improve the efficiency of task accomplishment as a student realizes their mistakes, rethinks them, and carefully prepares for a decision making. However, a further development in this factor can adversely affect the problem solving efficiency since the student's uncertainty and the fear of inconsistent solution to tasks increases. In this regard, the numerical value of the development level of the situational-destructive reflection factor is determined (Factor 2).

To determine the critical development level of the situational-destructive factor, which corresponds to the highest level of student academic performance, a regression model is developed using Equations (7)-(8). This is a model of the academic performance level (the average score of a student in all subjects per semester) dependence on the development level of the situational-destructive factor. Since the Bauman MSTU, the Gubkin University, and the MADI use different grading scales to assess students' knowledge (from 1 to 5 and from 1 to 100), in order to present the data in commensurate terms, all the scores were converted to a scale from 1 to 100. The principle of converting the 1 to 5 scale to 1 to 100 scale was as follows: an "adequate" rating corresponds to the score from 50 to 69 [32], therefore, the arithmetic mean value between 50 and 69 - 59.5 points - was used for the "adequate" rating; for the "good" rating, the arithmetic mean between 70 and 84 - 77 points - was used; for the "excellent" rating, the arithmetic mean between 85 and 100 - 92.5 points - was used.

The situational-destructive factor included interviewing questions No. 6, 8-10, 13, and 16; therefore, this factor development level was determined as the sum of a student's scores on the listed questions.

The model of student performance dependence on the development level of the situational-destructive factor is written as:

$$
Y=-0.04^{*} x^{2}+2.08^{*} x+63.01
$$

where $Y$ is the level of student academic performance (in points on a scale from 1 to 100); 
$x$ is the development level of the situational-destructive factor (in points).

The critical value of the development level of the situational-destructive factor is determined by finding the extremum of Function (10) through its derivative. The function extremum corresponds to the value of independent variable $x$, for which the derivative of function $Y^{\prime}=0$ or does not exist (Equation 11). The coefficient for $x^{2}$ has a negative value $(-0.04)$, therefore, the function extremum is its maximum value.

$$
\left\{\begin{aligned}
Y^{\prime}=-2 * 0.04 * x+2.08 * x=0 \\
x=26
\end{aligned}\right.
$$

The adequacy of the model developed for the dependence of student academic performance level on the development level of the situational-destructive factor is substantiated by the values of multiple correlation and determination coefficients that tend to 1 (0.91 and 0.83 , respectively), and the calculated value of Fisher test that exceeds the tabulated one (1.07).

As a result of finding the derivative, it is determined that the students' performance is maximized with the value of the situational-destructive factor of 26 points. A further increase in the reflection of students due to this factor will reduce their performance.

Out of the students who took part in the interviewing, the maximum value of the situational-destructive factor corresponds to 17 points, which is significantly lower than the optimum value ( 26 points). This means that an increase in the reflection levels in general and in the situational-destructive factor in particular will have a positive impact on the quality of problem solving and student academic performance.

Within the framework of the research, in order to ensure the reflective competence development, students are encouraged to use a case study technology as a method of analysis by means of providing information and ways to solve problems. A teacher forms cases on a topic with a description of a situation that is to be analyzed, with reflective problems to be solved. What is meant by reflective is assignments aimed at forming students' skills in independent analysis of task solutions, as well as skills of applying their own algorithms and actions (reflection). Some examples of reflective assignments for students are given below.

Task 1. This task aims to develop the ability to determine benchmarks that allow one to monitor the task performing process.

A bar with mass $m$ slides on an inclined plane that makes an angle $\alpha$ with the base. Without solving the problem, determine the control points (execution steps) aimed at finding the bar acceleration relative to the slide plane (OX). Complete the missing steps:

1) Graphic representation of the problem model;

2)?
3)?

4) Adding together the projections of forces acting on the bar and on the OX axis;

5)?

6)?

Task 2. The task aims to develop the ability to model the process of task accomplishment, to consider various case scenarios, to weigh all pros and cons.

At the top of a wedge located perpendicular to the base, a block is fixed (Figure 3 ), through which a system of two bodies is suspended ( 1 and 2), with a mass of 5 and $10 \mathrm{~kg}$, connected by a thread. The length of the wedge base is $0.3 \mathrm{~m}$, the height is $0.2 \mathrm{~m}$. Consider possible motion options for the wedge and the bodies on it, taking into account different parameter options of the block, the thread, and the wedge not specified in the problem situation.

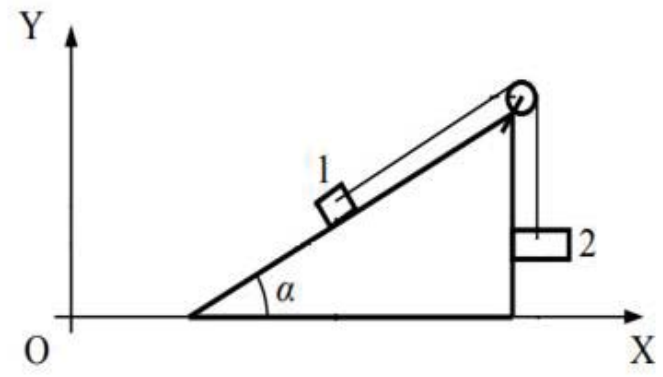

Figure 3

Task 3. The task aims to develop the ability to set a goal and to foresee the problem solution results.

Body $A$ is thrown with velocity $v$ parallel to OX axis. The trajectory of the body movement is shown in Figure 4. Describe the applied modeling objectives of this situation (the practical application possibility). What values are to be found for the task to be of practical importance and in what cases?

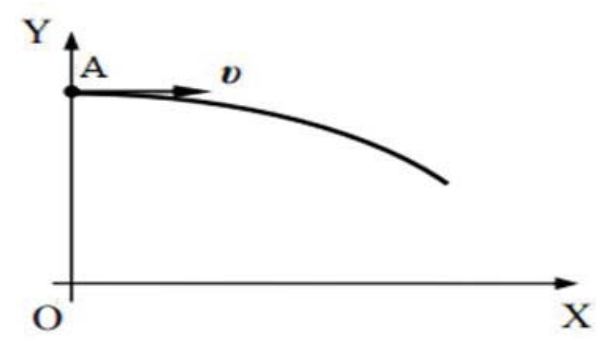

Figure 4

Task 4. The task aims to develop the self-analysis and critical thinking abilities.

Part 1. Body $A$ with mass $m$ is located on a horizontal plane with coefficient of friction $\mathrm{k}$. The bar is pulled by $a$ thread at a constant speed $v$. Find angle $\alpha$ between the thread and horizontal axis OX, whereby the thread tension is minimal (Figure 5). What is the thread tension in this case?

Part 2. Analyze the possibility of applying the solution 
you have obtained if it has been found that body A together with plane OX have been immersed in water.

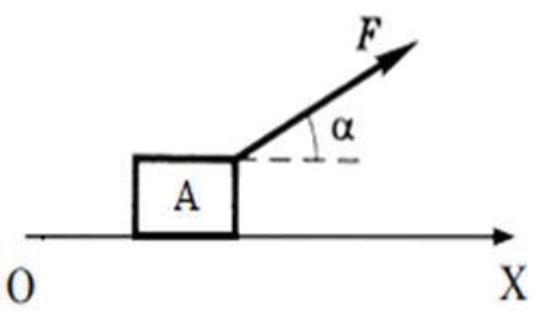

Figure 5

Task 5. The task aims to develop the ability for mental planning and for deliberate and calculated decision making.

Without solving the problem, prove possible situations whereby body $\mathrm{A}$, which is in the position shown in Figure 6 , does not slip from the top of a sphere with radius $R$.

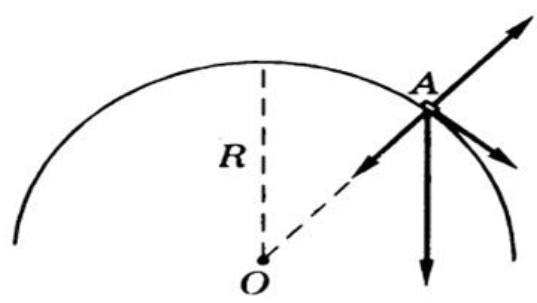

Figure 6

Reflective assignments are normally aimed at increasing the development level of the constructive factor of the reflective competence.

Along with reflective assignments in the educational process, it is advisable to use reflective-innovative methods and create a reflective educational environment that would ensure motivation for reflection and development of reflective skills in a person as an actor. It is application of these methods that would determine the development of the situational-destructive factor of the reflective competence.

One of the main reflective-innovative methods in education is various kinds of teacher training. Examples of training assignments for students are given below.

\section{Exercise Suggestion Box}

This is a training method for organizing group and individual work of students. It helps to assess the students' current knowledge and experience on a topic of discussion.

The procedure. The teacher draws a box on the board as a structure figuratively accumulating the background knowledge of students on the topic under consideration. Information is exchanged as follows:

1. The teacher asks a question to the audience about what the students know about the training subject, having formulated the main problematic issues on the subject;

2. Individual work begins. Each student summarizes everything they know on the problem in their notebook.

3. There is a common discussion organized among the students on the identified problems resulting in affinity groups formed based on like-mindedness. At the same time students identify the nuances of the

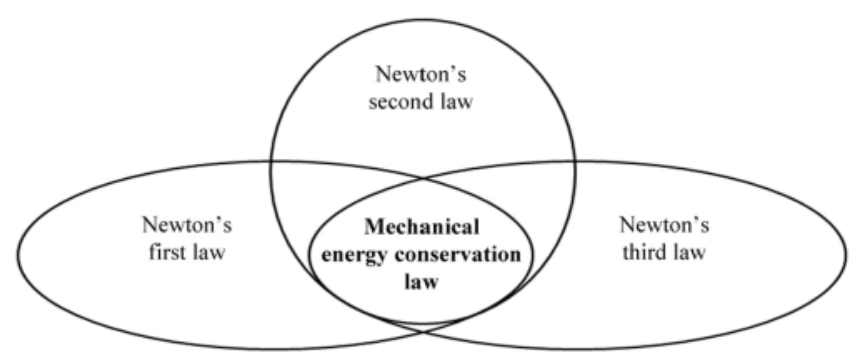

Figure 7: An example of Venn diagram

similarity of views on problems and the debatable aspects of disagreements;

4. By agreeing on a shared vision of the problematic aspects of the training session topic, each group of students articulates a general fact of the problem in turn, without reiterating those already mentioned.

5. The teacher records the ideas about the given topic problems, articulated and commented upon, in the "suggestion box" without further commenting on them, even in case of errors of judgment made by students;

6. Through a common discussion by the students and the teacher, the given views, facts, etc. related to the subject matter of the training session and uncompiled in the perception of students are linked into a logical chain.

Table 4: An example of how to draw up a Metaplan

\begin{tabular}{|c|c|}
\hline $\begin{array}{l}\text { 1. The existing challeng- } \\
\text { es. The reality: }\end{array}$ & 3. How should it be? \\
\hline $\begin{array}{l}\text { 2. Why do these prob- } \\
\text { lems exist? (Causes). } \\
\text { Why is it not actually the } \\
\text { way it should be? }\end{array}$ & $\begin{array}{l}\text { 4. Suggestions: how } \\
\text { to change the situation } \\
\text { and to solve the existing } \\
\text { problems? }\end{array}$ \\
\hline
\end{tabular}

7. The teacher presents the topic with a particular focus on the right and wrong ideas in the "suggestion box" generated by the students as they absorb and process new material and information;

8. At the end of the session, the students perform individual and group reflection of the performance.

\section{Exercise Venn Diagram}

This is a training technique that facilitates comparative analysis of terms, objects, and phenomena. It is aimed at development of the skills to summarize learning material and to reflect a student's own vision and perception of information. A chart consists of two or more intersecting circles. The part of the chart at the intersection of circles 
contains common features of concepts and phenomena of the topic under consideration, and the parts that do not intersect contain a list of differences (Figure 7).

The procedure.

1. The teacher provides information on the training subject and invites students to form a Venn diagram;

2. The students are split into pairs and fill only those parts of the circles that reflect differences of the phenomena and concepts under consideration on the given subject;

3. The participants organize themselves into small groups of four people to compare and supplement their diagrams;

4. Each small group compiles a list of characteristics that the students consider to be shared by the two phenomena under consideration.

\section{Exercise Metaplan}

This is a method to structure group discussions, to analyze a situation, to exchange opinions, to gather information on a specific issue, and to elaborate effective collective solutions. Metaplan is based on the principle of complete visualization of the process and discussion at all stages. When applying the method, students interact more, which makes the discussion more effective. The process occurs according to certain rules bringing the discussion to a required result.

The procedure.

1. The teacher announces a problem on a particular training session subject and writes it on the board divided into four sectors labeled by a post-it note of a certain color. In each sector, they write questions to be discussed by the students (Table 4);

2. All students are given post-it notes of four different colors (one of each color but additional notes are allowed if necessary). The participants are invited to individually jot down their ideas on each issue on the notes and add them in the sector of the respective color. The students are not supposed to discuss when doing the work;

3. The students are grouped by 2-5 people. Each group receives a task to work through the notes from a certain sector of the "metaplan": to sort out the notes, to group similar ones, to sort and rank the ideas in order of importance. For this purpose, the groups discuss the issue. After processing the notes, the participants elaborate on the wording of ideas and determine what other ideas can be added thereto;

4. The notes are then placed on the "metaplan" in a new order indicated by a group of students. For this, the suggestions can be copied from the notes to an A4 sheet, or the notes already written can be numbered. Each group is preparing to present the results of their work on the notes in its sector;

5. Presentation of the group works. During the dis- cussion and presentation of the work results by the groups of students, the entry of the last 4th table column can be presented in two columns, as follows: a) what can be done using the university's own resources at its level; b) what should be addressed to higher authorities, sponsors, etc.

6. Discussion, summarizing the work done.

\section{DISCUSSION}

Thus, based on the empirical research it has been identified that the majority of engineering students in the Russian universities under study have a low formedness level of the reflective competence. The level of reflection development in students increases with the training. The average number of first to fourth year students with a low level of reflection was $55.7 \%$ in the 2016-2017 academic year against $55.2 \%$ in 2017-2018 academic year.

The formation of student clusters by growth rates of reflection factors for the period under study has made it possible to conclude that the constructive and situational-destructive factors of reflective competence exhibit a proportional upward trend only in senior students and students studying psychological subjects. The dynamics of these factors in the first and third year students is observed to be inversely proportional. Given the fact that the number of students with a low level of reflection in course of the first to fourth years has not changed significantly over time, it can be attested that it is the age factor that has contributed to the reflection growth, while the educational process in Russia's modern traditional education system has not contributed to the development of reflective competence in students.

The importance of increasing the development level of reflection in students is evidenced by a direct substantial connection between the growth rates in the level of reflection and of academic performance of students at the universities under study: the correlation coefficient of these indicators calculated by Equation (6) is 0.71 . At a low and medium level of reflection in mechanic engineering students, revealed as a result of the interviewing, its increase would have a positive impact on the quality of problem solving and student academic performance. In this regard, the study has developed examples of training techniques for the first year mechanic engineering students of the second semester in the subject area of "Physics", aimed at developing the constructive and situational-destructive factors of reflection.

Reflective skills cannot be developed by conventional teaching methods, especially when solving problems. Thus, it is not a type of information to be transferred from the teacher to the student. The reflective competence develops by forming enabling reflective-developing conditions in the educational process. In this regard, reflective techniques should be integrated and adapted to the methods and content of the educational process in the higher education [6]. Therewith, a student's reflection on 
Table 5: The average values of first year students' reflection indices (2nd semester) as a result of the pedagogical experiment

\begin{tabular}{|c|c|c|c|c|c|c|c|c|c|}
\hline \multirow[t]{2}{*}{ University } & \multicolumn{3}{|c|}{$\begin{array}{l}\text { Factor } 1 \\
\text { (max } 55 \text { points) }\end{array}$} & \multicolumn{3}{|c|}{$\begin{array}{l}\text { Factor } 2 \\
\text { (max } 30 \text { points) }\end{array}$} & \multicolumn{3}{|c|}{$\begin{array}{l}\text { Reflection index } \\
\text { (max } 85 \text { points) }\end{array}$} \\
\hline & 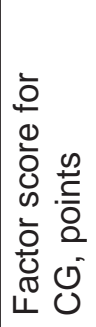 & 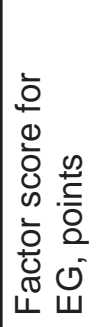 & 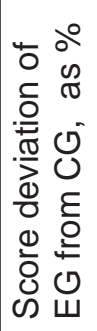 & 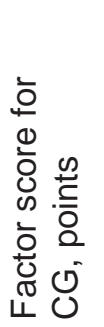 & 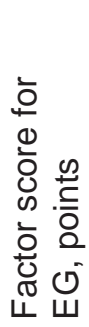 & 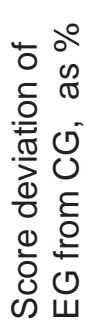 & 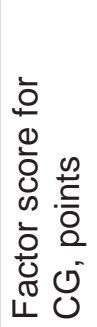 & 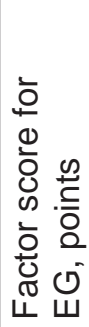 & 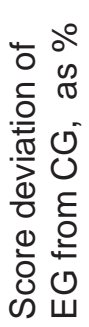 \\
\hline Bauman MSTU & 18.5 & 22.2 & 20.0 & 9.1 & 13.6 & 49.5 & 27.6 & 35.8 & 29.7 \\
\hline Gubkin University & 14.6 & 18.9 & 29.5 & 10 & 14.1 & 41.0 & 24.6 & 33 & 34.1 \\
\hline MADI & 12.3 & 19.6 & 59.3 & 7.1 & 12.9 & 81.7 & 19.4 & 32.5 & 67.5 \\
\hline
\end{tabular}

their individual mental activity should become the focus of the teacher's attention. In this regard, the reflective assignments developed in the research, when practically implemented in the educational process, determine the formation of such pedagogical learning environment that would contribute to the development of skills to recognize, comprehend, and rethink the reality in students, lead to formedness of intellectual operations and to a student's self-concept as an active participant in the reflection process.

The training assignments developed for students have proved their effectiveness in pedagogical practice in the process of personal and professional identity evolution, formation of independent organization and control skills, development of the self-organization ability. Since the trainings are primarily focused on collective cooperation of students among themselves and with the teacher, their active implementation in the educational process would promote students' confidence in making their own decisions or a less critical view when problems are solved incorrectly. The trainings are aimed at developing the self-knowledge and self-identification skills, so that in case of incorrect actions an individual is motivated to find the right decision rather than halt in the process.

The effectiveness of the assignments proposed to increase the level of reflection in students has been substantiated through a pedagogical experiment.

The experiment involved first year students majoring in "Machine-Building Technologies" at the Bauman MSTU; in "Mechanical Engineering" at the Gubkin University; in "Handling, Transport, Construction, Road-Building Machinery and Equipment" at the MADI, that were divided into two groups: control (CG) and experimental (EG) groups. The students in the groups formed Clusters 2 and 3 . The proposed reflective assignments and training for the development of professional and personal reflection in students in the process of solving problems were introduced in the educational process for the experimental group students, in the study of Physics. The control group of students was trained according to the regular discipline syllabus, without the use of additional assignments and trainings. At the end of the second semester, during which Physics was studied, students were asked to answer questions 1-17. Interviewing was carried out using these questions to determine the level of reflection

Table 6: Student's t-test values for the pedagogical experiment

\begin{tabular}{|c|c|c|c|c|}
\hline \multirow{2}{*}{ University } & \multicolumn{3}{|c|}{ Calculated Student's t-test values } & \multirow{2}{*}{$\begin{array}{l}\text { Tabulated Student's t-test } \\
\text { values at error level } \\
p=0.05\end{array}$} \\
\hline & By Factor 1 & By Factor 2 & By reflection index & \\
\hline Bauman MSTU & 4.35 & 5.28 & 9.63 & 1.9759 \\
\hline Gubkin University & 5.05 & 4.82 & 9.87 & 1.9719 \\
\hline MADI & 8.57 & 6.81 & 15.39 & 1.9731 \\
\hline
\end{tabular}


in engineering students in solving problems, its results being presented in the "Result" section. The pedagogical experiment results are presented in Table 5.

According to the outcome of the experiment, the reflection factor scores and the aggregate reflection index values for all the universities increased by an average of $43.8 \%$ for the experimental group of students. At the same time, as a result of the introduction of assignments and trainings aimed at the reflection development in students, the average level of reflection for each instructional year will increase from a low level, which falls within the range [0; 32], to an average of $(32 ; 53]$ points. The development level of reflection Factor 1 increased by $36.3 \%$, of reflection Factor 2 - by $57.4 \%$.

To assess the statistical significance of the pedagogical experiment results, the Student's t-test values were calculated using Equation (9). The calculation results per university are presented in Table 6.

The calculated Student's t-test values for Factors 1 and 2 and for the total reflection index for all the universities exceed the tabulated ones, which indicates the statistical significance of the pedagogical experiment at the $95 \%$ credible level.

It should be emphasized that the teacher's work technique in the system of higher education based on a reflective management approach is not so much that they teach and educate in the traditional sense as how much they update, inspire the desire and motivation of students for personal and professional development, further growth and self-improvement.

Reflective techniques for teaching students can be used at various stages of organization and control of students' classroom and independent work. In addition, the learning environment should be supplemented by the pedagogical reflection based on:

- A specially organized reflective activity characterized by purposefulness, objectivity, and awareness of a teacher, the transforming character and commonality in the construction of teaching techniques, the process of activity and its deliverables;

- Formation of a reflective environment as conditions for personality development in self-research and self-correction of professional and social-psychological resources of a teacher. The key direction is working with the teacher's existential phenomena, meanings, values in their individual activity; implementation of psychologically safe diagnostic assessment of professional competence and use of the results obtained for their professional development; development of creative uniqueness in the teacher;

- Inspiring relationship among the participants in reflective activities. In this case, the teacher acts as a subject of the reflective activity when the common activity takes place in a synchronous mode and all the participants enrich each other's activities while maintaining the individuality of their own actions. The result of such relationship in the reflective activity is mutual understanding, cooperation, co-creation, which, in turn, ensures the teacher's reflection development.

\section{CONCLUSION}

The following conclusions have been drawn based on the empirical study:

1. The interviewing among engineering students in Russian universities has attested to the fact that over $55 \%$ of the student population is characterized by a low level of the reflective competence. It has been identified that the student population dynamics with low reflection levels in course of the first to fourth instructional years is characterized by a slight increase, which is determined by the age factor. At the same time, the traditional national system of higher education in Russia does not contribute to the formation and development of the reflective competence in students.

2. Clusterization of students by the growth rate in the development of the constructive and situational-destructive factors of reflection determined their inversely proportional dynamics among the first and third year students at Russian universities. The reflective assignments elaborated to develop the constructive reflection factor would promote the development of self-regulation, self-esteem, and self-control in students through the formation of feedback in learning activities and establishing logical links between the educational material elements. Practical implementation of the proposed reflective trainings in the educational process would ensure the level development of the situational-destructive factor of students' reflection by forming skills to assess the results achieved and understanding their own actions, behaviors, and mental activity.

3. The substantiated criteria for the pedagogical reflection development as one of the main factors in the pedagogical conditions for the reflective competence development in students in the system of higher education in Russia are based on the organization of reflective activity and environment in the educational process, on inspiring and deepening the reflective relations. Such an approach would ensure an updated reflection in the teacher and would allow them to overcome pedagogical egocentrism, to gain personal self-consciousness that would lay the groundwork for internal changes, to transform obsolete professional stereotypes, and open the way for further professional growth.

The research findings presented in the paper will contribute to the formation of a mechanism for reflective management of the educational process and the development of reflectivity both in educators and in students. This, in turn, will allow the system of higher education in Russia to train competitive future professionals that 
would meet the current labor market requirements.

\section{REFERENCES}

1. Kankovskaya, A.R. (2016). Higher Education for Sustainable Development: Challenges in Russia. Procedia CIRP, vol. 48, 449-453.

2. Van Beveren, L., Roets, G., Buysse, A., \& Rutten, K. (2018). We all reflect, but why? A systematic review of the purposes of reflection in higher education in social and behavioural sciences. Educational Research Review, vol. 24, 1-9.

3. Tremblay, M.-C., \& Parent, A.-A. (2014). Reflexivity in PHIR: Let's have a reflexive talk! Canadian Journal of Public Health, vol. 105, no. 3, 221-223.

4. Federal state educational standards of higher education. (2018). Portal of Federal State Educational Standards of Higher Education.

5. On the Federal Targeted Program for the Development of Education for 2016-2020. (2015). The Decree of the Government of the Russian Federation as of May 23, 2015. N 497.

6. Pinchuk, A. N. (2017). Educational practices of modern students of the socio-humanitarian profile of education. PhD Thesis. Maikop: Trubilin Kuban State Agrarian University.

7. Sidorenko, T., \& Gorbatova, T. (2015). Efficiency of Russian Education Through the Scale of World University Rankings. Procedia - Social and Behavioural Sciences, vol. 166, 464-467.

8. Ponto, J. (2015). Understanding and Evaluating Survey Research. J Adv Pract Oncol., vol. 6, no. 2, 168171.

9. Rousseau, R., Egghe, L., \& Guns, R. (2018). Statistics. Becoming Metric-Wise, 67-97.

10. Ruiz, C.A.G., \& Luca, F. (2017). Fibonacci factoriangular numbers. Indagationes Mathematicae, vol. 28 , no. $4,796-804$

11. Menke, W. (2018). Factor Analysis. Geophysical Data Analysis (Fourth Edition), 207-222.

12. Suryani, D., Irwansyah, E., \& Chindra, R. (2017). Offline Signature Recognition and Verification System using Efficient Fuzzy Kohonen Clustering Network (EFKCN) Algorithm. Procedia Computer Science, vol. 116, 621-628.

13. Potekhina, N., Shulinina, Yu, Kuzmina, N., Potalisina, L., \& Sannikova, I. (2016). Correlational-regression Analysis Application for the Forecast of the Specialists with Higher Education Requirement in Russian Economy. International Journal of Economics and Financial Issues, vol. 6, no. 2, 617-620.

14. Mishra, S., \& Datta-Gupta, A. (2018). Regression Modeling and Analysis. Applied Statistical Modeling and Data Analytics. A Practical Guide for the Petroleum Geosciences, 69-96.
15. Alós-Ferrer, C., \& Hügelschäfer, S. (2016). Faith in intuition and cognitive reflection. Journal of Behavioural and Experimental Economics, vol. 64, 6170.

16. Brown, B., Holt-Macey, S., Martin, B., Skau, K., \& Vogt, E.M. (2015). Developing the reflective practitioner: what, so what, now what. Currents in Pharmacy Teaching and Learning, vol. 7, no. 5, 705-715.

17. Côté, J.-F. (2015). George Herbert Mead's concept of society: A critical reconstruction. Paradigm publishers, New York.

18. Clatterbuck, H. (2016).Darwin, Hume, Morgan, and the veraecausae of psychology. Studies in History and Philosophy of Science Part C: Studies in History and Philosophy of Biological and Biomedical Sciences, vol. 60, 1-14.

19. Shchedrovitskiy, G. P. (2015). Organizational and managerial thinking. Ideology, methodology, technology. Artemiy Lebedev Studio, Moscow.

20. Ahmed, M.H. (2018). Reflection for medical undergraduate: learning to take the initiative to look back to go forward. Journal of Hospital Management and Health Policy, vol. 2, no. 31, DOI: http://dx.doi. org/10.21037/jhmhp.2018.05.07

21. Smith, R.A., Andrews, S., Oliver, C., \& Chambers-Evans, J. (2018). Putting reflective practice into action: A case study. Journal of Nursing Education and Practice, vol. 8, no. 10, 36-47.

22. Stîngu, M., Ulrich, C., \& Vrăsmaş, E. (2015). Using Reflective Practice to Enhance Professional Development Through Written, Spoken and Visual Materials. Procedia - Social and Behavioural Sciences, vol. 180, 1207-1214.

23. Karpa, J.V., \& Chernomas, W.M. (2013). Nurse Educators' Perspectives on Student Development of Reflection for Psychiatric Mental Health Nursing Practice. International Journal of Nursing Education Scholarship

24. Zelazo, P.D. (2015). Executive function: Reflection, iterative reprocessing, complexity, and the developing brain. Developmental Review, vol. 38, 55-68.

25. Karpov, A.V. (2018). System and genetic regularities in the development of metacognitive entities.

26. Karpov, A.V., Bashaeva, T.V., Koneva, E.V., Markova, E.V., Myshkin, I.Yu., Orel, V.E., Razumovskaya, O.L., Skityaeva, I.M., Subbotin, L.Yu., Cheremoshkin, L.V. (2018). Psychology of labour. U-write, Moscow.

27. Manakhov, S. V. (2013). Reflexion as a leading component of psycho-prophylaxis of deviant behaviour of adolescents. Bulletin of Moscow State Open University. Series: Psychological Sciences, vol. 1, 7580.

28. Rapatskiy, B. I. (2014). Reflection as one of the mechanisms for the development of the personality 
of adolescents. The Humanitarian Vector, vol. 1, no. 37, 149-153.

29. Martynova, A. V. (2015). The development of the need for reflection as a condition for the formation of professional self-awareness of the future teacher of an elementary school. Modern problems of the science and education, vol. 1, no. 1.

30. Anisimov, O.S. (2016). Methodological problems of the consolidation dynamics of the Russian society: a civilized approach. Kogito-Tsentr, Moscow.

31. Semenov, I.N. (2015). Self-observation reflexivity and introspection personology: to ontology and methodology of the reflexive psychology of individuality. Bulletin of Moscow University, vol. 4, 98-113.

32. Regulation on the rating system of knowledge assessments. (2018). Gubkin Russian State University of Oil and Gas. 